\title{
Antimalarial Activity of Some Plants Used in Traditional Medicine in Uganda
}

\section{OBUA', O. ODYEK ${ }^{2}$, W.W. ANOKBONGGO', S.K. APIO ${ }^{3}$, P. WAAKO' AND J.W. OGWAL-OKENG ${ }^{*}$}

'Department of Pharmacology and Therapeutics, Makerere University, P.O. Box 7072, Kampala, Uganda.

${ }^{2}$ Department of Pharmacy, Makerere University, P. O. Box 7072, Kampala, Uganda.

${ }^{3}$ Natural Chemotherapeutics: Research Laboratory, P.O. Box 4862, Kampala, Uganda.

This work was done to identify some of the plants used in the treatment of malaria in Uganda and to investigate their efficacy in the in-vitro assays. Plumbago zeylenica and Cryptolepis sanguinolenta showed marked activity on the chloroquine resistant and chloroquine sensitive strains of Plasmodium falciparum. Plumbagin, a quinone, was isolated from Plumbago zeylenica, and found to have antimalarial activity with $\mathrm{IC}_{50}$ of $178 \mathrm{ng} / \mathrm{ml}$ on chloroquine sensitive and $188 \mathrm{ng} / \mathrm{ml}$ on chloroquine resistant strains. Cytotoxicity assays on $\mathrm{KB}$ cell lines indicated that the extract was selective for Plasmodium falciparum. The Selective Index was 5 in both strains of Plasmodium falciparum.

It was concluded that some of the plants used for malaria contain compounds with antimalarial activity, which can be useful leads for the development of new antimalarial drugs.

Key Words: Antimalarial activity, Plumbago zeylenica, Cryptolepis sanguinolenta, plumbagin

\section{INTRODUCTION}

Malaria is the most important public health problem in Uganda. It accounts for $25 \%$ of patient attendances, $20 \%$ admissions and $15 \%$ in-patient deaths [1]. Children below 5 years and pregnant women are the most severely affected by the disease. Malaria is becoming increasingly difficult to control because the parasites are rapidly developing resistance to the available drugs [2]. Therefore, there is urgent need for new drugs with novel modes of action. The drugs are also not readily accessible to the community due to the low socio-economic status and the poor distribution of health facilities. This has led to extensive use of herbal remedies for treatment of diseases including malaria.

The traditional healers in Uganda recognized the medicinal value of plants and used them for treatment of various ailments, including fever, possibly due to malaria [3]. Plants that are extensively used in Uganda for treatment of fevers include Chasmanthera dependens, Cryptolepis sanguinolenta, Harrisonia abyssinica, Plumbago zeylenica, Schkuhria pinnata and Secamone africana [4-7]. This study was done to screen these plants and any isolated compound(s) for antimalarial activity and to investigate the toxicity levels.

\section{METHODOLOGY}

\section{Plant Materials}

Plants investigated were selected on the basis of their traditional use. Roots of $C$. sanguinolenta, $P$. zeylanica, $C$. dependens, $H$. abyssinica and $S$. africana and aerial parts of $S$. pinnata were collected from their natural habitat. Botanical identification was done at the Natural Chemotherapeutics Research Laboratory, Kampala and confirmed by a botanist at the Makerere University herbarium where voucher specimens were deposited.

\section{Extraction}

Dry powdered plant material $(300 \mathrm{~g})$ was extracted by soaking in chloroform $(500 \mathrm{ml})$ for $24 \mathrm{~h}$ with occasional shaking. The solvent was removed using a rotary evaporator to afford 
semisolid extracts.

\section{Bioassay-guided fractionation of $P$. zeylenica}

The chloroform extract of $P$. zeylenica demonstrated the highest antiplasmodial activity $\left(\mathrm{IC}_{50} 1375.0\right.$ and $4642.0 \mathrm{ng} / \mathrm{ml}$ on chloroquinesensitive (D6) and chloroquine-resistant (W2) strains, respectively) and was therefore selected for further fractionation. The crude extract $(3.5 \mathrm{~g})$ was fractionated by column chromatography on silica gel. The column was eluted with petroleum ether followed by increasing concentrations of chloroform, acetone and methanol in petroleum ether, then finally washed with methanol. The eluents were examined by thin layer chromatography and fractions with similar $R_{f}$ values combined to give 27 fractions (F1-F27). Antimalarial bioassay test located the highest activity in fraction 4 . The bioactive fraction was purified by recrystallisation from methanol to give an orange crystalline compound ( $1.1 \mathrm{mg} .0 .36 \%$ ). The compound was verified to be 5-hydroxy-2methyl-1,4-naphthoquinone, plumbagin (figure 1), by comparing the physical (TLC, $R_{f}$ value, HPLC retention time and melting point) and spectroscopic (UV, IR, MS and NVR) data with those of authentic sample.

\section{Bioassays}

Antimalarial bioassay tests were used to select the active chloroform extract and to follow the active fraction during the fractionation of $P$. zeylenica extract. In vitro cytotoxicity assay was performed to determine the level of toxicity and selectivity of plumbagin.

\section{Antimalarial Assays}

Antimalarial activity of the crude extracts and plumbagin was assessed using the in vitro radioisotope-incorporation method [8] as modified by Likhitwitayawuid et al. [9]. The tests were done using suspension of chloroquine-resistant

(W2) and chloroquine-sensitive (D6) $P$. falciparum infected red blood cells $(0.6 \%$ parasitaemia, $1 \%$ cell haematocrit). The materials were tested over a concentration range of 14 $10,000 \mathrm{ng} / \mathrm{ml}$ in 96 -well microtitre plates. Control experiments were similarly set with culture medium (RPMI-1640, GIBCO, Chicago, U.S.A.) as the drug-free control. Chloroquine was used as a positive control antimalarial drug.

The microtitre plates were incubated for $24 \mathrm{~h}$ at $37^{\circ} \mathrm{C}$ in a sealed chamber in an atmosphere of $5 \% \mathrm{CO}_{2}, 5 \% \mathrm{O}_{2}$ and $90 \% \mathrm{~N}_{2}$. After the incubation, $0.5 \mu \mathrm{Ci}$ of $\left[{ }^{3} \mathrm{H}\right]$ hypoxanthine (New England Nuclear, Boston, U.S.A.) was added to each well, and the plate returned to the sealed chamber at $37^{\circ} \mathrm{C}$ for another $18 \mathrm{~h}$. The contents of the micro wells were then harvested into a glass fibre filtamat (Filtermat A), (Wallac Oy, Turku Finland) using a Tomtec 96-well harvester (Tomtec, Orange, Connecticut, U.S.A.). Filtermats were dried, immersed in $4 \mathrm{ml}$ scintillation fluid in a sealed plastic pouch. Radioactivity in each well was counted using 1450 MicroBeta $^{\text {TM }}$ Liquid Scintillation Counter (Wallac Oy). The concentration that inhibited parasite-specific incorporation of $\left[{ }^{3} \mathrm{H}\right]$ hypoxanthine by $50 \%\left(\mathrm{IC}_{50}\right)$ was determined by non-linear regression analysis. The drug-free control defined the $100 \%$ incorporation of the radioactivity.

\section{Assays for Cytotoxicity}

Plumbagin was evaluated for level of toxicity and degree of selectivity for Plasmodium falciparum by the in vitro cytotoxicity test, using the human oral epidermoid carcinoma (KB) cell lines and stained with sulforhodamine $B$ (SRB assay) as described by Skehan et al. [10]. The cell culture (KB) was incubated with plumbagin at concentrations ranging from $0.16-20 \mu \mathrm{g} / \mathrm{ml}$, in 96-well microtitre plates, for $72 \mathrm{~h}$. Cell growth was assessed by measuring the cellular protein content using Sulforhodamine B. After removing the unbound dye with $1 \%$ acetic acid, proteinbound dye was extracted with $10 \mathrm{mM}$ unbuffered Tris base ( $\mathrm{pH} \mathrm{10)}$ and the optical density (OD) was measured at $515 \mathrm{~nm}$ using ELISA plate reader. The $\mathrm{TC}_{50}$ was calculated using non-linear regression analysis (percent survival vs. concentration). The Selective Index (SI) was therefore determined as a ratio of $\mathrm{TC}_{50}$ to $\mathrm{IC}_{50}$. 


\section{RESULTS AND DISCUSSIONS}

The plants screened for antimalarial activities are presented in table 1 . Activity was defined as $\mathrm{IC}_{50}$ value of $\leq 5000 \mathrm{ng} / \mathrm{ml}$. $\quad P$. zey/enica extract demonstrated the highest activity, the $\mathrm{IC}_{50}$ was found to be $4642 \mathrm{ng} / \mathrm{ml}$ and $1375 \mathrm{ng} / \mathrm{ml}$ on W2 and D6 parasites, respectively. C. sanguinolenta also demonstrated antimalarial activity, especially on D6 strain $\left(\mathrm{IC}_{50}=2772.9 \mathrm{ng} / \mathrm{ml}\right)$, but poor activity against $\mathrm{W} 2$ strain. $C$. dependens, $H$. abyssinica, $S$. pinnata and $S$. africana had minimal activity on the tested strains. This might mean that the plants have no antimalarial effect or may act as antipyretics or immune modulators. It is also possible that the active compound exists as pro-drug that may need biotransformation in vivo to the active form. This study also confirmed the findings of other authors that have isolated cryptolepine, a very potent antimalarial compound from C. sanguinolenta $[11,12]$.

The active compound isolated from $P$. zeylenica was determined to be 5-hydroxy-2-methyl-1, 4naphthoquinone with the common name plumbagin (figure 1) and its antimalarial and cytotoxicity is shown in table 2 .

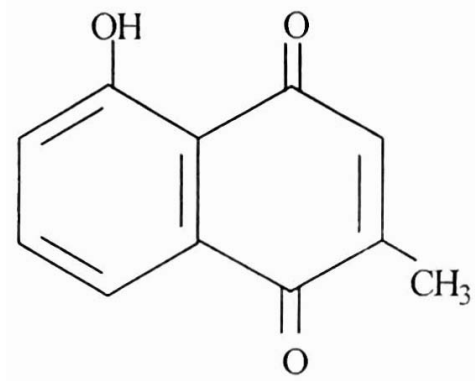

Figure 1: The structure of plumbagin
The $\mathrm{KB}$ cell line is used to determine the selectivity of a compound and discriminate compounds that selectively inhibit Plasmodium and hence act as general toxins. It was therefore used to define the in vitro therapeutic index, in this case referred to as the "Selective Index". SI for antimalarial activity is therefore defined as the ratio of the medium toxic dose in the $\mathrm{KB}$ cell lines $\left(\mathrm{TC}_{50}[\mathrm{~KB}]\right)$ to the medium inhibitory concentration in $P$. falciparum $\left(\mathrm{IC}_{50}[P\right.$. falciparum]). The $\mathrm{SI}$ serves as an in vitro indicator of clinical safety in the absence of the in vivo therapeutic index. SI is therefore used to prioritize active test samples, and in guiding bioassaydirected fractionation $[13,14]$.

Plumbagin showed high activity against both chloroquine sensitive and resistant strains of the parasite. The cytotoxicity value of $1000.00 \mathrm{ng} / \mathrm{ml}$ gave the selective index (SI) of 5.5 and 5.3 on D6 and W2 parasites, respectively. The compound was therefore more than five times selective for the malaria parasites (Table 2),

Table 2: Antimalarial activity and cytotoxicity of plumbagin

\begin{tabular}{|l|l|l|l|l|l|}
\hline Compound & \multicolumn{2}{|c|}{$\begin{array}{c}\text { Antimalarial } \\
\text { activity IC } \\
\text { (ng/m) }\end{array}$} & $\begin{array}{l}\text { Cytotoxicity } \\
\text { TC }_{5 \mathbf{5}}(\mathrm{g} / \mathrm{ml})\end{array}$ & \multicolumn{2}{|c|}{$\begin{array}{c}\text { Selective } \\
\text { Index }\end{array}$} \\
\cline { 2 - 6 } & $\mathbf{D 6}$ & $\mathbf{W} 2$ & $\mathrm{~KB}$ & $\begin{array}{l}\text { KB/ } \\
\text { D6 }\end{array}$ & $\begin{array}{l}\text { KB/ } \\
\text { W2 }\end{array}$ \\
\hline Plumbagin & 178.12 & 188.8 & 1000.0 & 5.50 & 5.30 \\
\hline Chloroquine & 4.50 & 44.40 & $\mathrm{~N} / \mathrm{D}$ & $\mathrm{N} / \mathrm{D}$ & $\mathrm{N} / \mathrm{D}$ \\
\hline
\end{tabular}

N/D $=$ Not determined; D6 $=$ Chloroquine sensitive $P$. falciparum; W2 $=$ Chloroquine resistant $P$. falciparum; $\mathrm{KB}=$ Human oral epidermoid cell lines.

Table 1: Antimalarial activity of some of the plants used for malaria

\begin{tabular}{|c|c|c|c|c|}
\hline \multirow[t]{2}{*}{ Botanical name (Family) } & \multirow{2}{*}{$\begin{array}{l}\text { Plant } \\
\text { Part } \\
\end{array}$} & \multirow{2}{*}{$\begin{array}{l}\mathrm{CHCl}_{3} \text { extract } \\
\text { yield }(\%)\end{array}$} & \multicolumn{2}{|c|}{$\mathrm{IC}_{50}(\mathrm{ng} / \mathrm{ml})$} \\
\hline & & & D6 & W2 \\
\hline inptolepis sanguinolenta (Lindl.) Schltt (Asclepidiaceae) & $\mathrm{R}$ & 2.5 & 2772.9 & $>5000.0$ \\
\hline Plumbago zeylenica Linn. (Plumbagianaccae) & $\mathrm{R}$ & 2.0 & 1375.0 & 4642.0 \\
\hline Chasmanthera dependens (Hochst) (Menispermaceae) & $\mathrm{R}$ & 2.4 & $>5000.0$ & $>5000.0$ \\
\hline Harrisonia abyssinica (Oliv.) (Simaroubaceae) & $\mathrm{R}$ & 2.5 & $>5000.0$ & $>5000.0$ \\
\hline Schklumia pinnata (Lam) Thell (Compositac) & $\overline{A P}$ & 4.5 & $>5000.0$ & $>5000.0$ \\
\hline Secamone africana (Oliv.) (Ascelpidiaceae) & $\mathrm{R}$ & 3.0 & $>5000.0$ & $>5000.0$ \\
\hline Chloroquine (Positive control) & & & 2.4 & 105.1 \\
\hline
\end{tabular}

$\mathrm{R}=$ Root. $\mathrm{AP}=$ Aerial Parts. $\mathrm{D} 6=$ Chłoroquine sensitive $P$. falciparum strain. $\mathrm{W} 2=$ Chloroquine resistant $P$. falciparum strain 
The antimalarial activities of naphthoquinones and quinone-containing compounds have been known for a long time [15]. Plumbagin was first isolated from Plumbago scandens by workers in Brazil who were investigating the plant for its anti-inflammatory and anti-Parkinsonian effects [16]. Likhitwitayawuid et al. reported isolation of plumbagin from Nepenthes thorelli (Nepenthaceae), investigated its structure-activity relationships and concluded that the quinone structure was essential for the antimalarial activity of the compound[9]. It has been suggested that plumbagin produces antimalarial action by inhibiting the mitochondrial NADH dehydrogenase $[17,18]$.

This study has been able to justify the use of some of these plants as antimalarial drugs by the traditional healers in Uganda. It confirms that the plants contain compounds that can inhibit multiplication of the parasites and therefore act as drugs for the treatment of malaria. The study has also demonstrated that plumbagin is selective for the malaria parasites and can be used safely as an antimalarial drug.

The problem of using herbs has been the validation of efficacy, safety and quality control of the preparations. This study has demonstrated the antiplasmodial efficacy of the extracts of $C$. sanguinolenta and $P$. zeylenica as well as the antimalarial efficacy and safety of plumbagin. It will now be possible to standardize and control the quality of the herbal preparations of $P$. zeylenica and therefore improve the management of malaria in the community.

\section{CONCLUSION}

The result of this study was fed back to the traditional healers in a workshop. Plumbagin will be used to standardize and control the quality of the herbal preparations of $P$. zeylenica. The healers agreed to participate in a clinical trial of the standardized herbal preparations, including $P$. zeylenica.

\section{ACKNOWLEDGMENTS}

This research was supported financially by the ACA Program of the Rockefeller Foundation. The spectroscopic confirmation of the structure of Plumbagin was done in the University of Illinois at Chicago with financial support from the Fulbright Fellowship Program.

\section{REFERENCES}

[1] Ministry of Health, Uganda, Uganda National Plan for Action for Malaria Control (third draft) (1993) CDC, Entebbe.

[2] J.F. Trape. Am. J. Trop. Med. Hyg. 64 (2001) 12-17.

[3] W.W. Anokbonggo, R. Odoi-Adome and P.M. Oluju. Bulletin of the World Health Organization, 68 (1990) 359.

[4] J.W. Ogwal-Okeng. PhD Thesis, Studies on the Antimalarial Activities of Some Ugandan Medicinal Plants, (1998) Makerere University, Kampala.

[5] J.E Adjanohoun., M.R.A., Ahyi, J.W. Ogwal-Okeng, N. Mubiru, C. Amai, J. Morakinyo, H.K. Lutakome, C.L.A. Johnson, L. Ake-Assi, Z.O. Gbile, M.A. Alia and A. Sofowora. Traditional Medicine and Pharmacopoeiae: Contribution to Ethnobotanical and Floristic studies in Uganda. OAL STRC. Lagos (1993).

[6] N.K. Mubiru, C.A. Amai, J.W. OgwalOkeng, A.B. Kakooko, J.B. Mutyaba, A.M. Alia, S.K. Apio and E.S. Nduga. Ethnomedicine in Uganda Series:

Ethnobotanical and Traditional Healers Survey (1994) Part 1-25.

[7] R. Bukenya-Ziraba, P. Doenges, J.W. Ogwal-Okeng, J. Lejoly and P. Duez, Medicinal Plants Sub-sector Review: Pharmacopeia Promoting Program. Final Report (1996), Brussels, Belgium.

[8] R.E. Desjardins, C.J. Canfield, J.D. Haynes and J.D. Chuley. J.D. Antimicrob. Agents Chemother. 16 (1979) 710. 
[9] K. Likhitwitayawuid, R Kaewamamatawong, N. Ruangrungsi and J. Krungkrai, Planta Medica. 64 (1998) 237.

[10] P. Skehan, R. Storeng, D. Scudiero, A. Monks, J. McMahon, D. Vista, J.T. Boskesch, S. Kenney and M. R. Boyd. J. Nat'l Cancer Inst. 82 (1990) 1107.

[11] A. Paulo, E. T. Gomes and P. J. Houghton. J. Nat. Prod. 58 (1995) 1485.

[12] K. Cimanga, T. Bruynet, L. Pieters, M. Claeys, A. Vlietinck, Tetrahedron Lett. 37 (1996) 1703.

[13] C.K. Angerhofer, G. M. Konog, A.D. Wright and $O$. Sticher. Selective Screening of Natural Products: A resource for the discovery of novel antimalarial compounds. In: Atta-ur-Rahman (Ed), Advances in Natural Product Chemistry
(1992), 311. Harwood Academic Publishers, Chur, Switzerland.

[14] C. W. Wright and J. D. Phillipson. Phytother. Res. 4 (1990) 127.

[15] Lin Tai-Shun, Zhu Li-Ya, Xu Shi-Ping, A. A. Divo and A. C. Sartorelli. J. Med. Chem. 34 (1991) 1634.

[16] J. Bhattacharyya and V. R. de Carvalho, Phytochem. 25 (1986) 764-765.

[17] J. Krungkrai, R. Kanchanarithisak, S. R. Krungkrai, S. Rochanakij. Exp. Parasitol. 100 (2002) 54.

[18] N. Suraveratum, S. R. Krungkrai, P. Leangaramgul, P. Prapunwattana, J. Krungkrai, Mol. Biochem. Parasitol., 105 (2002) 215. 